\title{
On the Social Background, Difficulties and Strategies of College English Teaching in China Today
}

\author{
Yingjie Guo \\ School of Foreign Languages, \\ Shaanxi Normal University \\ Xi'an, China \\ guoyingjie@snnu.edu.cn
}

\begin{abstract}
To probe into the current situation of college English teaching and its development in China, this thesis employs the scientific investigations and authorized works as references. Firstly, it relates to the social background of fulfilling college English teaching in China and finds that college English teaching still plays a significant role in Chinese nation, society, and individual life. Besides, the thesis makes a survey about the difficulties encountered in college English teaching, pointing out that as for China, changing the long-standing concepts of education among people needs a course; as for colleges and universities, meeting the demands of the national development implies flexibility and competence; and as for students and teachers, the educational reform requires determination and persistence. Last, the thesis works out the corresponding strategies and holds that more sophisticated research and studies should be carried out reasonably. To sum up, the thesis reveals that the core value and the ultimate goal of college English teaching is "human development".
\end{abstract}

Keywords-college English teaching; social background; difficulties; strategies; China

\section{INTRODUCTION}

College English teaching has been available in China for many years. Fundamentally, it is one of the essential and valuable measures fulfilled in the course of the development of Chinese education. Nowadays, no one can deny such a fact that college English teaching has already triggered off enormous changes in Chinese society and are working out more surprising achievements in various fields of Chinese life[1]. The benefits include 1) College English teaching is one of the crucial factors to stimulate Chinese nation to get access to international superiorities and frontiers; 2) College English teaching serves as a potential force to make Chinese society develop in a dynamic and efficient way; 3) College English teaching brings abundant opportunities to college students and makes them acquire more advanced knowledge in their study so as to communicate actively with the outside world; 4) and therefore, the overall spirit and morale of Chinese people turn out to be refreshing and lovely in the long run[2,3]. However, as a Chinese saying goes, "it is wise to stay prepared against adversities in times of peace and success". To enhance the accomplished prosperity, Chinese nation has to be reasonable and alert enough[3]. And accordingly, the undertakings, such as re-evaluating the role of college English teaching in new environment, reconsidering its influences for the sake of the better development, re-establishing its unique functions to adapt itself in a new era, etc, should be critically taken into account and responsibly concerned. In this case, the related discussions on the social backgrounds, difficulties and strategies of college English teaching in China today are proved to be both meaningful and nascent.

\section{SOCIAL BACKGROUND OF COLLEGE ENGLISH TEACHING IN CHINA TODAY}

\section{A. To Be in Line with International Conventions, China Has to Integrate Herself into the World System. And College English Teaching Will Do Good to the Progress.}

As we all know, English has been regarded as the most popular international language in the world. In the fields of politics, economics, culture, history, philosophy, science, techonology and the like, English acts as a vehicle or a bridge for people to communicate and exchange ideas, especially among different countries that maintain unique traditions. Quite a few European, African and Asian countries have taken English as their major foreign language or even official language. As for China, to be in line with international conventions, teaching English as a second language has obviously become a national policy to improve Chinese people's comprehensive qualities and capabilities while college English teaching is taken then as a recognized assignment, referring to the fact that millions of college students are the hopes and successors of Chinese holy national cause. What's more, to integrate herself into the world system, China has worked out and is working out a number of influential edicts and regulations to guarantee the effects of college English teaching in the east and west, north and south. Particularly since 1980s, college English teaching has been an independent discipline or subject in China that takes the responsibility of demanding Chinese students to absorb foreign knowledge eagerly. However, after approaching in the 21st century, college English teaching began to be confronted with favourable circumstances as well as unexpected challenges, which required Chinese government, educational 
institutions, teachers and students to work together for the long-term destinations. Thus, the new rounds of reforms and innovations have been fulflled to demonstrate their potential charms[2,4].

\section{B. To Satisfy the Diverse Demands of Chinese People, the} Society Has to Provide Colorful Ways of Life. And College English Teaching Will Be Part of the Practices.

One basic truth is that any nation and society cannot exist without open-mindedness. The point here is that all social development and progress must be associated with flexible and harmonious atmosphere. Instances can be negotiated accordingly. One hundred years ago, Chinese people began to realize the importance of learning English in schools and practiced the idea step by step; Fifty years ago, learning English was a necessity among students and it gradually became a compulsory discipline; thirty years ago, Chinese people did their utmost to make English a fashion to favor their interest; and now, Chinese people hold English as a way of life as if they cannot live without English. Perhaps that is one of the critical reasons why parents eagerly ask their children to learn English at very young age, in kingdergartens or in primary schools. To satisfy the diverse demands of Chinese people, the society has to take effective actions. Establishing the authorized role of college English teaching and letting it funcntion smoothly have proved themselves the worthwhile efforts. Meanwhile, a variety of social organizations participate in the colorful activities. The educational authorities, along with administrative departments, intend to carry out more enhanced measures to cater for the essential requirements of the social groups, which aims to compromise the relationship between opportunities and latent challenges. In terms of the rewarding practices, college English teaching, among other things, brings amazing achievements. So transparently, it needs the deeper levels of discussions and explorations[4,5].

\section{To Make Dreams Come True, One Has to Be Earnest and Down-to-earth in Acquiring Knowledge. And College English Teaching Offers One A Pair of Wings.}

Frankly speaking, not only the college students but also their teachers have the strong desires to make their individul dreams come true, which means that students' learning as well as teachers' teaching relate to a central theme that achieving what they have done respectively will be the channel to demonstrate their talents and efforts. Therefore, "one” here associates both the role of "struggling students" and that of "hard-working teachers", and implies that "one" has to be earnest and down-to-earth. Particularly in the globalized and modernized world, Chinese people are faced with the integration of science and technology, the cooperation of international economies, and the innovation of ethnic communications. Besides, with the education scale expanding rapidly in all corners of China and China's accession to the World Trade Organization, each one of Chinese people has the responsibility of displaying their knowledge as well as characters. For those teaching or studying at colleges and universities, college English teaching offers them a pair of wings. That's to say, "one" has to face the music, admit the changing realities and take the advantage of the resources available on campus. In that particular environment, college English teaching provides "one" with a window to look outside and view the scenery basically distinctive from their own. Thanks to it, many Chinese students, and teachers as well, are going abroad to study further or do researches and harvest unexpected surprises beyond their original imgination.

\section{Difficulties of COLLEGE ENGLish TeACHING IN CHINA TODAY}

To be honest, college English teaching in China has encountered its bottleneck today and certain difficulties embarrass the rapid development of China, and harrass that of colleges and universities too. Due to the realities, college students and teachers run into their dilemmas afterwards.

\section{A. As for China, Changing the Long-standing Concepts of Education among People Needs a Course.}

It is an undenying fact that English education plays an indispensable role in advancing Chinese nation and making China a unique being in the modern world, especially after the reform and opening-up policy was made throughout China in 1978. Since 1999, Chinese government has invested much more money than before in higher education programs, including those of the English teaching and learning. In 2001 and 2003, Ministry of Education of China issued systematic documents/directions to regulate the development of the academic disciplines, which regards the sophisticated research and study about college English teaching. In 2008, the corresponding reforms and innovations took place gradually in the specific fields of college English teaching. While in 2012, the Examination Board of CET-4 and CET-6(EBC) made the scheduled reforms and innovations even further and more deeply by referring to the new national situation and revolutions. And at present, college English teaching still has its experiments while more relevant research is going on and on. Basically, all measures regarding college English teaching have demonstrated their potentials and power. Yet the truth is that changing the long-standing concepts of education among people is not an easy job to fulfill. Instead, it requires Chinese government and the attached departments to consider such problems as, to mention a few, how to balance the relationship between Chinese language teaching and English language teaching, Chinese culture teaching and English culture teaching, Chinese tradition acqusition and English civilization study, and the like[2,3,6].

\section{B. As for Colleges and Universities, Meeting the Demands of the National Development Implies Flexibility and Competence.}

We have to confess that some Chinese colleges and universities still maintain traditional styles to teach college English. On the one hand, they provide students with the environment and knowledge in an oversimplified way, which results in the cramming or forced-feeding method of language teaching; on the other hand, they stress more on the abstract academic study and ignore the importance of associating students' knowledge with the realistic needs of the society, which reveals that students' learning in calss is obviously 
seperated from the acutal demands of the real life as if the knowledge acquired in school has nothing to do with the very requirements of the material world. Additionally, the unpleasing phenomena like "teaching dumb English", "high pay, low return", "learning without targets”, etc still exist whereas students' ideas are completely divorced from reality, and the functions of colleges and universitities are not fully stimulated, thus leaving educational resources ivory-towered. The issues, including how to make colleges and universities get away from the pure pursuit of certificates, how to meet the basic demands of national development, how to keep colleges' and universities' flexibility and competence, etc should be seriously concerned. Besides, the controversial test-oriented educational mechanisms will be another aspect that the educational institutions must reconsider and take care of $[4,6]$.

\section{As for Students and Teachers, Educational Reform Requires Determination and Persistence.}

If the educational reform aims to improve the quality of college English teaching, the involvement of students and teachers in class seems significant and neccesery. But there are also some difficulties that make both students and teachers reluctant to change themselves. The point here is that changing means giving up the accustomed way of life. One aspect is that students consciously or unconsciously keeps the habit of utilitarian learning. Those who study for high scores, credits, scholarship and prizes are not the few. Instead, they strive to learn the knowledge that can help them pass CET-4 and CET6. Once passing the exams, they would lose the driving force and put English books on the shelf. To some extent, it is a phenomenon among students that they are short of life planning and career designs, focus more on the immediate interests while ignoring their long-term goals. Another aspect is that teachers, especially the already-proved excellent teachers, do not like so many changes or reforms in their teaching because they are not confident about the results that educational reforms will bring to them. They believe in the positive fulfillment of "student-oriented teaching style" yet they prefer to follow the ways they are familiar with[2,3]. Or they want to have some revolutions but when they meet the students who study srely for certificates and prizes, they will run into dilemmas[4]. So obviously, the educational reforms, if taken sincerely, will demand both the students' and the teachers' determination and persistence.

\section{StRategies of College English Teaching IN ChinA TODAY}

Based on the overall analysis of the background and the difficulties of college English teaching above, it is urgent to work out the essential strategies to cope with the unsatisfying situation.

\section{A. On the Side of Chinese Nation and Society, Learning from Advanced Countries and Integrating the Well-calculated Experiences into Chinese Way of Life Are the Tasks to Continue.}

Although the nation-wide reforms and innovations may meet with frustrations and barriers, the belief in the potential goodness and advantages caused by the reforms and innovations should be enhanced in China, considering the truth that successful undertakings have taken place in the higher education of advanced countries like America, France, Britain, Germany, Canada, Australia, Russia, etc. Besides, the objective of fostering all-round persons for the sake of China's future will be another significant responsilibity[2,7]. To make China Dream come true, it is reasonable for Chinese government to re-evaluate the role and function of college English teaching in the new era while reconsidering whether the teaching philosophy employed within is suitable or not[3,5]. Besides, stressing much on the instrumental aspects of college English teaching is not enough, so to speak, elaborating the glamor of humanitarian effects and highlighting its priorities will be a neccesity. Perhaps, merely through practising the humanistic education can we conform a true scientific education and raise Chinese people's qualities. The tendency here is as clear as what the educational humanists advocate all the time because "the core value and the ultimate goal of education is human development”[6].

\section{B. On the Side of Colleges and Universities, Optimizing} Resource Distributions and Cultivating Compound Talents Are the Ways to Strengthen Their Competitiveness.

To adapt themselves to the globalized atmosphere of the world and guarantee their efficient development, Chinese colleges and universitites may have to accept the duty of establishing fine management and operation mechanisms. Apart from optimizing the resource distributions in a flexible way, exauhsting the wisdom and efforts of colleges and universities to cultivate compound talents will be considered as a valuable try which is worthy of practcing throughout the whole educational process. Since the existence of human education aims to find and shape those who desire to harvest both abilities and moralities, the various educational institutions, including colleges and universities of course, may exert their high moral standards and extend their outstanding traditions. The corresponding models include English extracurricular activities, multimedia network classroom, movie-motivated plays, speech-activated competitions, etc[6]. The forms and contents are inclined to rely on the active participation of all the members who fill themselves with the confidence that innovations will bring them lots of fun and benefits. Definitely, reforming the teaching modes as well as the environment also implies that colleges and universitites have to abandon over-simplified teaching styles and return to the humane strategies that can compromise both the learning effects and the utilizing effects. In brief, multi-purposes and experiments of education wait for more validations and confirmations[1,5].

\section{On the Side of Students and Teachers, Transforming Their Conservative Thoughts into the Positive Power and Creating the Compatible Teaching Styles by Referring to China's Unique Nationality Are the Experimental Efforts.}

Without any doubt, both students and teachers long for ideal states of learning and teaching, which may generate harmonious communications between them. To achieve good effects, students are encouraged to carry out diversified learning styles. Such practices as autonomous learning, social 
researches, interactive debates, academic exchanges at home and abroad, etc will be the channels and vehicles to demonstrate students' talents. Or students are sponsored to set up their own English Learning Center, English Broadcasting Station, English Study Studio, etc., which flexibly concern English culture, history, geography, science, fashion, art and so on so forth and make college English learning intersting and colorful[4,6]. Meanwhile, teachers may introduce kinds of teaching approaches into their classes and make their teaching go forward as an art. At present, the recognized teaching approaches include MOOC, Flipped Classrooms, Microlectures, Task-based Learning, Collaborative Learning, Inquiry-based Learning, etc. Apart from the foreign teaching approaches, Chinese scholars also have their innovations and experiments. The most recognized one now must be Bisection Learning Approach initiated by Professor Zhang Xuexin, a distinguished scholar in Fudan University. These teaching approaches aim to create pleasant atmosphere to satisfy the individual requirements by following the scheduled educational principles that are designed to do good to students' personality development[2,6]. In that case, making a reasonable evaluation means keeping pace with the changes of the teaching art.

\section{CONCLUSION}

College English teaching has worked a lot of wonders in China and helped both college students and teachers realize their dreams in different levels. Though there are difficulties and drawbacks that make our nation, society, educational institutions, students and teachers unsatisfied, we still believe that college English teaching is one of the crucial factors to strengthen Chinese nation's comprehensive capabilities and confidences, not only concerning the cultural aspects but also the psychological counterparts. Language input is perhaps merely one issue to achieve while cultural and morale output belongs to another brilliant task to accomplish. Of course, there are some scholars who have observed that college English teaching may mislead students into concentrating too much on its instrumental side and make them blindly strive for the high score of CET-4 or CET-6 while ignoring the true value of practicing English learning and teaching[7]. Thus the problems within the educational system will stimulate the potential power of college English teaching and allow students and teachers, scholars and researchers alike, to try enterprising spirits and daring efforts to reach ambitious destinations. Frankly, college English teaching takes English not just as a tool, instead, it involves the truth that English learning relates to the improvement of students' all-round abilities. College English teaching will bring Chinese people the opportunities to get access to the outside world and offer them the ways to examine their own cultures. This will become a new theme worthy of more sophisticated discussion and more standardized study. However, the core value and the ultimate goal of English education cannot be ignored, that is "human development". To reach the destination, more relevant research and studies should be carried out.

\section{ACKNOWLEDGMENT}

This research was financially supported by Shaanxi Social Science Fund(2014J11), 2016 Shaanxi Normal University Research Fund of "Teachers' Teaching Innovation and Practice” (JSJX2016Y007) and 2017 Shaanxi Normal University Research Fund for Graduate Education and Reform (GERP-17-33).

\section{REFERENCES}

[1] S. R. Wang, H. X. Wang, "An investigation of the current situation of college English teaching in China and its reforms and development," Foreign Languages in China, vol. 5, pp. 4-11, August 2011.

[2] S. R. Wang, Report of the Development of Foreign Language Education in Chinese Colleges and Universities. Shanghai: Shanghai Foreign Language Education Press, 2008.

[3] W. Mao, Q. L. Sheng, "Focus on the teaching designs: a key to enforce the reform of college English teaching in China,” Foreign Language Research, vol. 1, pp. 106-109, February 2016.

[4] J. B. Huang, Y. Z. Shao, "Outlet of the reform of college English teaching,” Foreign Language World, vol. 4, pp. 20-22. August 1998.

[5] J. M. Xia, "On the challenges of teachers in the reforms of college English teaching," Foreign Languages in China, vol. 2, pp. 4-6, April 2007.

[6] R. Q. Liu, Research on Foreign Language Teaching Reforms in Chinese Colleges and Universities and the Development Strategies. Beijing: Foreign Language Teaching and Research Press, 2003.

[7] X. M. Zheng, Q. Y. Jiang, “A study of 'teachers' belief' in the reforms of college English teaching,” Foreign Language World, vol. 6, pp. 16-22. December 1998.. 